Special Section: Noninvasive Imaging of Processes in Natural Porous Media

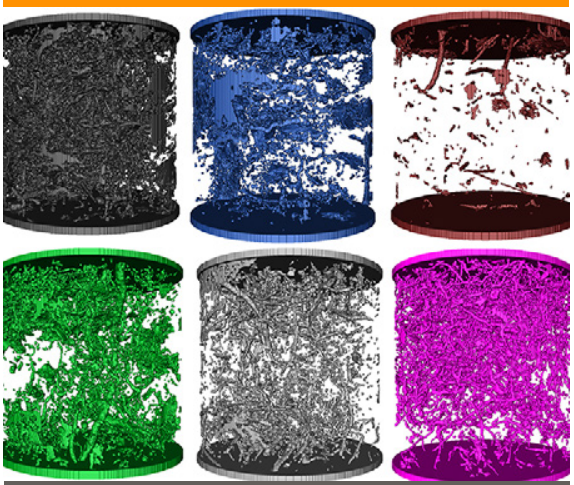

Core Ideas

- Vis-NIR can be used for estima-

tion of soil physical and structural properties.

- Structural parameters are better predicted using vis-NIR than pedotransfer functions.

- Vis-NIR can be a fast and reliable method for predicting soils' transport behavior.

S. Katuwal, C. Hermansen, M. Knadel Dep. of Agroecology, Aarhus Univ. Blichers Allé, Tjele, 8830-Denmark; P. Moldrup, Dep. of Civil Engineering, Aalborg Univ., Sofiendalsvej 11, Aalborg, 9200-Denmark; M.H. Greve and L.W. de Jonge, Dep. of Agroecology, Aarhus Univ., Blichers Allé, Tjele, 8830-Denmark. *Corresponding author (Sheela.Katuwal@agro.au.dk).

Received 28 June 2016

Accepted 20 Feb. 2017.

Citation: Katuwal, S., C. Hermansen, M. Knadel, P. Moldrup, M.H. Greve, and L.W. de Jonge. 2018. Combining $\mathrm{X}$-ray computed tomography and visible near-infrared spectroscopy for prediction of soil structural properties. Vadose Zone J. 17:160054. doi:10.2136/vzj2016.06.0054

(c) Soil Science Society of America.

This is an open access article distributed under the CC BY-NC-ND license (http://creativecommons.org/licenses/ by-nc-nd/4.0/).

\section{Combining X-ray Computed Tomography and Visible Near- Infrared Spectroscopy for Prediction of Soil Structural Properties}

\author{
Sheela Katuwal,* Cecilie Hermansen, Maria Knadel, \\ Per Moldrup, Mogens H. Greve, and L.W. de Jonge
}

Soil structure is a key soil property affecting a soil's flow and transport behavior. X-ray computed tomography (CT) is increasingly used to quantify soil structure. However, the availability, cost, time, and skills required for processing are still limiting the number of soils studied. Visible near-infrared (vis-NIR) spectroscopy is a rapid analytical technique used successfully to predict various soil properties. In this study, the potential of using vis-NIR spectroscopy to predict X-ray CT derived soil structural properties was investigated. In this study, 127 soil samples from six agricultural fields within Denmark with a wide range of textural properties and organic $C(O C)$ contents were studied. Macroporosity (>1.2 $\mathrm{mm}$ in diameter) and $\mathrm{CT}_{\text {matrix }}$ (the density of the field-moist soil matrix devoid of large macropores and stones) were determined from X-ray CT scans of undisturbed soil cores (19 by $20 \mathrm{~cm}$ ). Both macroporosity and $\mathrm{CT}_{\text {matix }}$ are soil structural properties that affect the degree of preferential transport. Bulk soils from the 127 sampling locations were scanned with a vis-NIR spectrometer (400-2500 nm). Macroporosity and $\mathrm{CT}_{\text {matrix }}$ were statistically predicted with partial least squares regression (PLSR) using the vis-NIR data (vis-NIR-PLSR) and multiple linear regression (MLR) based on soil texture and OC. The statistical prediction of macroporosity was poor, with both vis-NIR-PLSR and MLR $\left(R^{2}<0.45\right.$, ratio of performance to deviation $[R P D]<1.4$, and ratio of performance to interquartile distance $[R P I Q]<1.8)$. The $C T_{\text {matrix }}$ was predicted better $\left(R^{2}>0.65\right.$, RPD $>1.5$, and RPIQ $>2.0)$ combining the methods. The results illustrate the potential applicability of vis-NIR spectroscopy for rapid assessment/prediction of $\mathrm{CT}_{\text {matrix }}$.

Abbreviations: $\mathrm{CT}$, computed tomography; $\mathrm{CT}_{\text {matrix }}$ density of field-moist soil matrix devoid of large macropores and stones; HU, Hounsfield units; MLR, multiple linear regression; OC, organic carbon; PCA, principal component analysis; PLSR, partial least squares regression; RPD, ratio of performance to deviation; RPIQ, ratio of performance to interquartile distance; vis-NIR, visible near-infrared.

Soil structure is a key soil property affecting the ability of soils to carry out various functions such as the production of food, feed, and biomass and the storage and movement of water, gas, and solutes (Bronick and Lal, 2005). Soil structure is usually defined as the spatial arrangement of pore and particle networks in soil, and it is quantified using various approaches. The quantification of soil structure, in terms of the soil-pore system, ranges from the direct measurement of soil pore networks to indirect measurement of the functional behavior of the soil structure and is derived from the flow and transport experiments.

X-ray computed tomography $(\mathrm{CT})$ is being extensively explored for its ability to directly quantify soil structure in terms of soil-pore networks (Al-Raoush and Willson, 2005; Helliwell et al., 2013; Katuwal et al., 2015c; Paradelo et al., 2016; Rab et al., 2014; Schlüter et al., 2011). Various pore network characteristics such as porosity, connectivity, pore diameter, and pore shape have been quantified to assess the soil structure (Larsbo et al., 2014; Luo et al., 2010; Vogel et al., 2010), which, in turn, has been used to study and predict flow and transport processes in soils (Anderson, 2014; Köhne et al., 2011; Larsbo et al., 2014; Naveed et al., 2015). Because of the nondestructive nature of the analysis, X-ray CT 
allows three-dimensional data to be combined with structural data obtained from the other methods (Katuwal et al., 2015a) and for the dynamic processes to be visualized and analyzed (Cnudde and Boone, 2013; Koestel and Larsbo, 2014; Luo et al., 2008; Mooney, 2002). With the advancement of the technology, computational power, its greater affordability, and ease of accessibility, there is an increasing tendency to use X-ray CT in soil science research (Vaz et al., 2014). At present, several challenges such as accessibility, availability, cost, and the need for image processing techniques still limit the widespread use of the technology or use of X-ray CT in largescale studies. Because of this, pedotransfer functions, developed from the relationship between soil structural properties and basic soil physical properties, are still used in many prediction functions.

Diffuse reflectance spectroscopy using the visible to near-infrared (vis-NIR, 400-2500 $\mathrm{nm}$ ) region is an inexpensive and rapid means of measuring soil properties that requires little or no sample preparation and offers the possibility of estimating several soil properties with a single spectrum (Viscarra Rossel et al., 2006). The basic principle behind vis-NIR spectroscopy is that different components of soils absorb energy in the visible range of the electromagnetic spectrum, mainly due to electronic transitions of atoms, and in the NIR range from weak overtones and combinations of vibrational features that have fundamental absorptions due to molecular vibrations ( $\mathrm{C}-\mathrm{H}, \mathrm{O}-\mathrm{H}, \mathrm{H}_{2} \mathrm{O}, \mathrm{N}-\mathrm{H}$, and $\mathrm{CO}_{3}$ groups) in the mid-infrared region (Viscarra Rossel et al., 2006). Soil color, soil moisture, OC, particle size, and soil mineralogy are the basic soil constituents and properties affecting spectral reflectance and absorbance the most (Stenberg et al., 2010). Visible-near-infrared spectroscopy has been used for both qualitative and quantitative analysis of soils (Du and Zhou, 2008). It is increasingly used for the prediction of soil physical, chemical, and biological properties, particularly soil OC, clay content and mineralogy, soil $\mathrm{pH}, \mathrm{N}$, extractable $\mathrm{P}, \mathrm{K}, \mathrm{Fe}$, and cation exchange capacity (Cambou et al., 2016; Nocita et al., 2013; Peng et al., 2014; Sørensen and Dalsgaard, 2005; Stenberg et al., 2010; Viscarra Rossel et al., 2006). The successful application of vis-NIR spectroscopy to determine soil properties such as texture and OC or organic matter, which have a primary response in the vis-NIR region, has opened the doors for the prediction of various other soil properties that do not have a primary response in the vis-NIR region but are correlated to the basic soil physical properties (Brown et al., 2006). More recently, new applications of vis-NIR spectroscopy have been explored, ranging from the estimation of soil-water retention (Babaeian et al., 2015a, 2015b; Santra et al., 2009) to soil structural quality (Askari et al., 2015; Cécillon et al., 2009), soil aggregate size distribution and stability (Gomez et al., 2013; Sarathjith et al., 2014), and soil engineering properties (Waruru et al., 2014).

While X-ray CT provides a direct measure of the soil-pore system and structural parameters, vis-NIR spectroscopy provides the prediction of various soil properties based on the spectral response of the soil constituents in the vis-NIR region. Soil structural properties are controlled by different factors such as soil properties, climate, soil and crop management, and the activity of plant roots and soil fauna (Bronick and Lal, 2005). The structural properties, in turn, affect the hydraulic properties of the soil and therefore the basic soil properties and/or the structural properties are often used for the prediction of the hydraulic properties (Børgesen et al., 2008; Dexter, 2004; Rawls, 1983). Under saturated conditions, the hydraulic conductivity and solute transport are largely controlled by macropores (pores larger than $\sim 30 \mu \mathrm{m}$ in equivalent cylindrical diameter [Jarvis, 2007]) and their characteristics (Naveed et al., 2015; Vogel, 2000) because they transport fluids and solutes at much faster rates than the surrounding soil matrix. However, under soil moisture conditions close to saturation, the soil hydraulic properties and solute transport depend on whether macropores in the soil are activated or not (Vanderborght et al., 2000). Recent studies by Paradelo et al. (2016) and Katuwal et al. (2015b) have shown that under steady-state and near-saturated conditions, the initiation of macropore flow depends on the density of the field-moist soil matrix $\left(\mathrm{CT}_{\text {matrix }}\right.$ ), which can be derived using nondestructive $\mathrm{X}$-ray $\mathrm{CT}$. The $\mathrm{CT}_{\text {matrix }}$ represents the compactness of the field-moist soil matrix and is affected by the abundance of pores in the soil matrix, the properties of the soil particles, and the moisture content of the soil during scanning and thus is closely related to soil bulk density under field-moist conditions (Katuwal et al., 2015b; Lamandé et al., 2013). Vogel et al. (2006) and Vogel and Roth (2003) showed that the prediction of flow and transport through soils requires information on both the macrostructure and microstructure, where the quantification of the macrostructure should include information on the three-dimensional topology (obtained from X-ray CT), while the microstructure heterogeneities can be averaged and replaced by effective descriptions. Quantification of macropores with X-ray CT has often shown that macropore characteristics such as macropore size and connectivity are highly correlated with macroporosity (Katuwal et al., 2015c; Larsbo et al., 2014). Thus macroporosity as a measure of macrostructure and $\mathrm{CT}_{\text {matrix }}$ as the effective microstructural parameter have been chosen as structural properties for this study.

The aim of this study was to evaluate the use of vis-NIR spectroscopy for the estimation of soil structural properties relevant to solute transport quantified using X-ray CT (macroporosity $\geq 1.2 \mathrm{~mm}$ and field-moist matrix bulk density, $\mathrm{CT}_{\text {matrix }}$ ) of soil from six agricultural fields within Denmark. The hypothesis was that vis-NIR spectroscopy can be used for the rapid assessment of soil structural properties. In this study, X-ray CT was used for characterizing the aspects of soil structure most relevant to water and solute movement. The $\mathrm{CT}_{\text {matrix }}$ and macroporosity were quantified using X-ray CT and were then estimated using vis-NIR spectroscopy.

\section{Materials and Methods}

\section{Field Sites and Soils}

Topsoils from six agricultural fields in Denmark (Fig. 1) were studied. The fields represent a wide range in soil texture from sandy to 


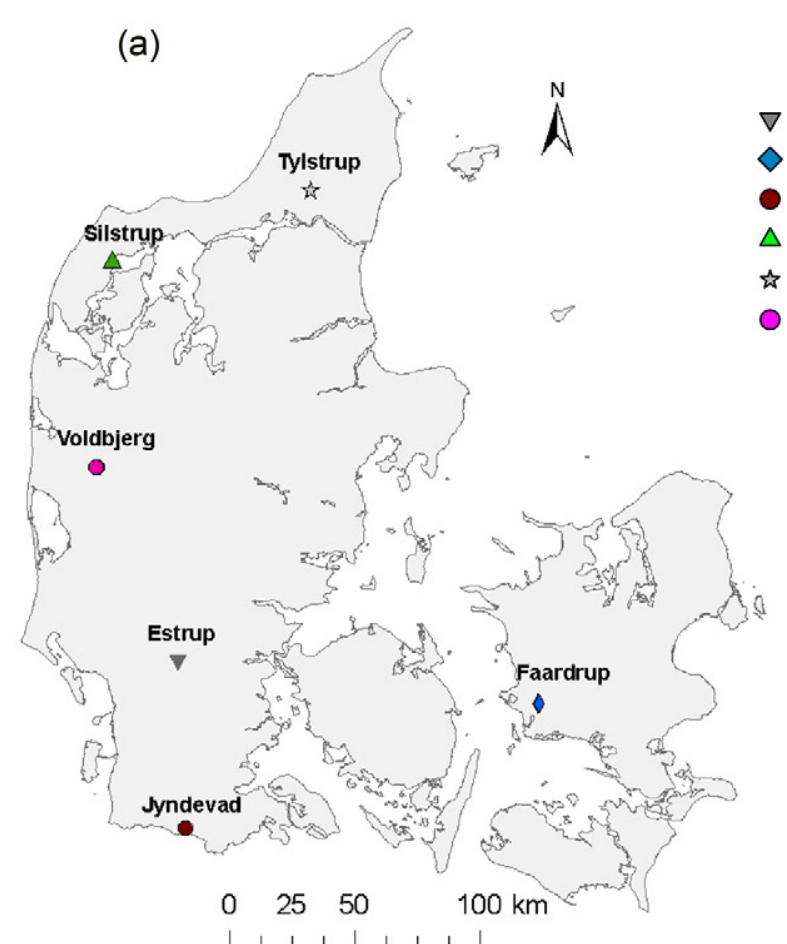

(b)

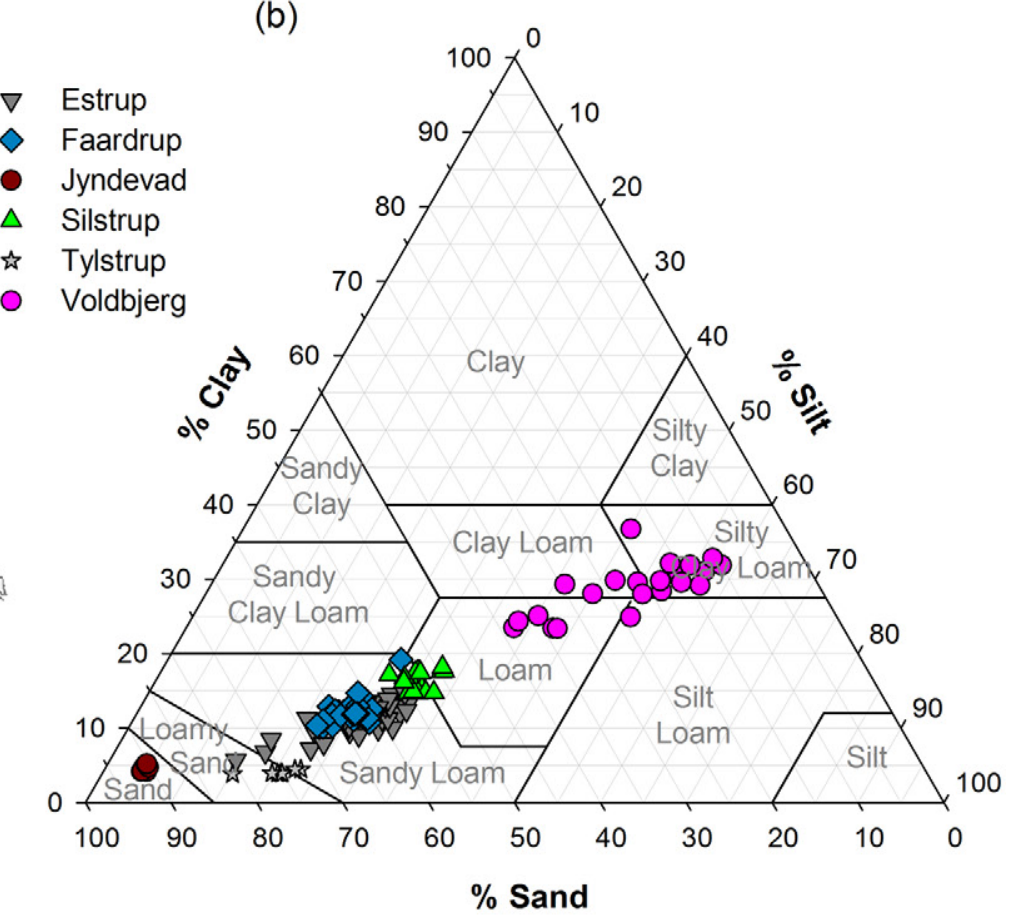

Fig. 1. (a) Field sites within Denmark and (b) texture of the field soils classified according to the USDA classification system.

silty clay (Table 1). The field site in Estrup $\left(55^{\circ} 29^{\prime} 10^{\prime \prime} \mathrm{N}, 9^{\circ} 4^{\prime} 9^{\prime \prime} \mathrm{E}\right.$, $1.26 \mathrm{ha}$ ) is characterized by a sandy loam soil. The field is located on a clay till core developed with deposits of different age and composition (Lindhardt et al., 2001). Further information on the site can be found in Paradelo et al. (2016). The Faardup field site $\left(55^{\circ} 19^{\prime} 1^{\prime \prime} \mathrm{N}, 11^{\circ} 20^{\prime} 34^{\prime \prime} \mathrm{E}, 2.3 \mathrm{ha}\right)$ is characterized by a sandy loam. It is developed on a meltwater sand aquifer, which is overlaid with Weichselian clay till deposits (Lindhardt et al., 2001). For more information on the site characteristics, see Soares et al. (2015). The Jyndevad field ( $54^{\circ} 53^{\prime} 37^{\prime \prime} \mathrm{N}, 9^{\circ} 7^{\prime} 12^{\prime \prime} \mathrm{E}, 2.39 \mathrm{ha}$ ) is a homogeneous field characterized by sandy soil. The field is relatively flat and is dominated by Quaternary deposits of late glacial freshwater sands (Lindhardt et al., 2001). Details on the site were presented by Knadel et al. (2016). The Silstrup field $\left(56^{\circ} 55^{\prime} 56^{\prime \prime} \mathrm{N}, 8^{\circ} 38^{\prime} 44^{\prime \prime} \mathrm{E}\right.$, $1.7 \mathrm{ha}$ ) is sandy clay loam and sandy loam. It is dominated by clay till deposits from the Weichselian glaciation (Lindhardt et al., 2001). Details on the site were presented by Norgaard et al. (2013). The soil in Tylstrup $\left(57^{\circ} 10^{\prime} 47^{\prime \prime} \mathrm{N}, 9^{\circ} 57^{\prime} 24^{\prime \prime} \mathrm{E}, 1.08 \mathrm{ha}\right)$ is a loamy sand. The field is located on fine-grained marine sand deposited in the shallow arctic Yoldia Sea (Lindhardt et al., 2001). Finally, the Voldbjerg site $\left(56^{\circ} 18^{\prime} 71^{\prime \prime} \mathrm{N}, 8^{\circ} 54^{\prime} 87^{\prime \prime} \mathrm{E}, 1.4 \mathrm{ha}\right)$ is characterized by a large gradient in clay content. The soil developed in glacial lake deposits in a moraine landscape from the Saale glaciation.

Cylindrical soil columns (19 cm inner diameter and $20 \mathrm{~cm}$ high) were collected from each field by pushing aluminum cylindrical cores into the topsoil with the assistance of a hydraulic press mounted on a tractor. The surrounding soil was then removed and the soil columns extracted, trimmed at the bottom, sealed at both ends with plastic caps, and stored at $2{ }^{\circ} \mathrm{C}$ until the experiments were performed. A total of 127 soil columns from the six field sites were studied (Estrup, 45; Faardrup, 27; Jyndevad, 9; Silstrup, 17; Tylstrup, 7; and Voldbjerg, 22 soils). Sampling at the different fields was performed between 2010 and 2014 (Estrup, September 2012; Faardrup, April 2011; Jyndevad, spring 2012; Silstrup, October 2010; Tylstrup, February 2014; and Voldbjerg, December 2013) when the soils were expected to be close to field capacity. Additionally, bulk soils were collected from the top $20 \mathrm{~cm}$ at each sampling point and mixed thoroughly for the determination of texture, OC content, and vis-NIR measurements.

\section{Soil Texture and Organic Carbon}

The soil texture was determined by a combination of wet sieving and hydrometer methods (Gee and Or, 2002) on 2-mm sieved soils. The OC content was measured on ball-milled samples with a FLASH 2000 Organic Elemental Analyzer (Thermo Fisher Scientific).

\section{X-ray Computed Tomography Scanning and Analysis}

A medical scanner (Siemens Biograph True Point 64, Siemens AG) was used for scanning the undisturbed soil cores (voltage $120 \mathrm{kV}$, exposure $740 \mathrm{mAs}$, and X-ray tube current $333 \mathrm{~mA}$ ). The soils were scanned horizontally, and reconstruction was done using filtered back-projection. The reconstructed image had a 512 by 512 pixel resolution, and each pixel measured 0.43 by $0.43 \mathrm{~mm}$. The slice thickness was $0.6 \mathrm{~mm}$. The contrast of the images or the pixel intensity is expressed as CT values or numbers in Hounsfield units $(\mathrm{HU})$ and is related to the linear attenuation coefficient 
Table 1. Physical and structural properties of the soils from the different fields.

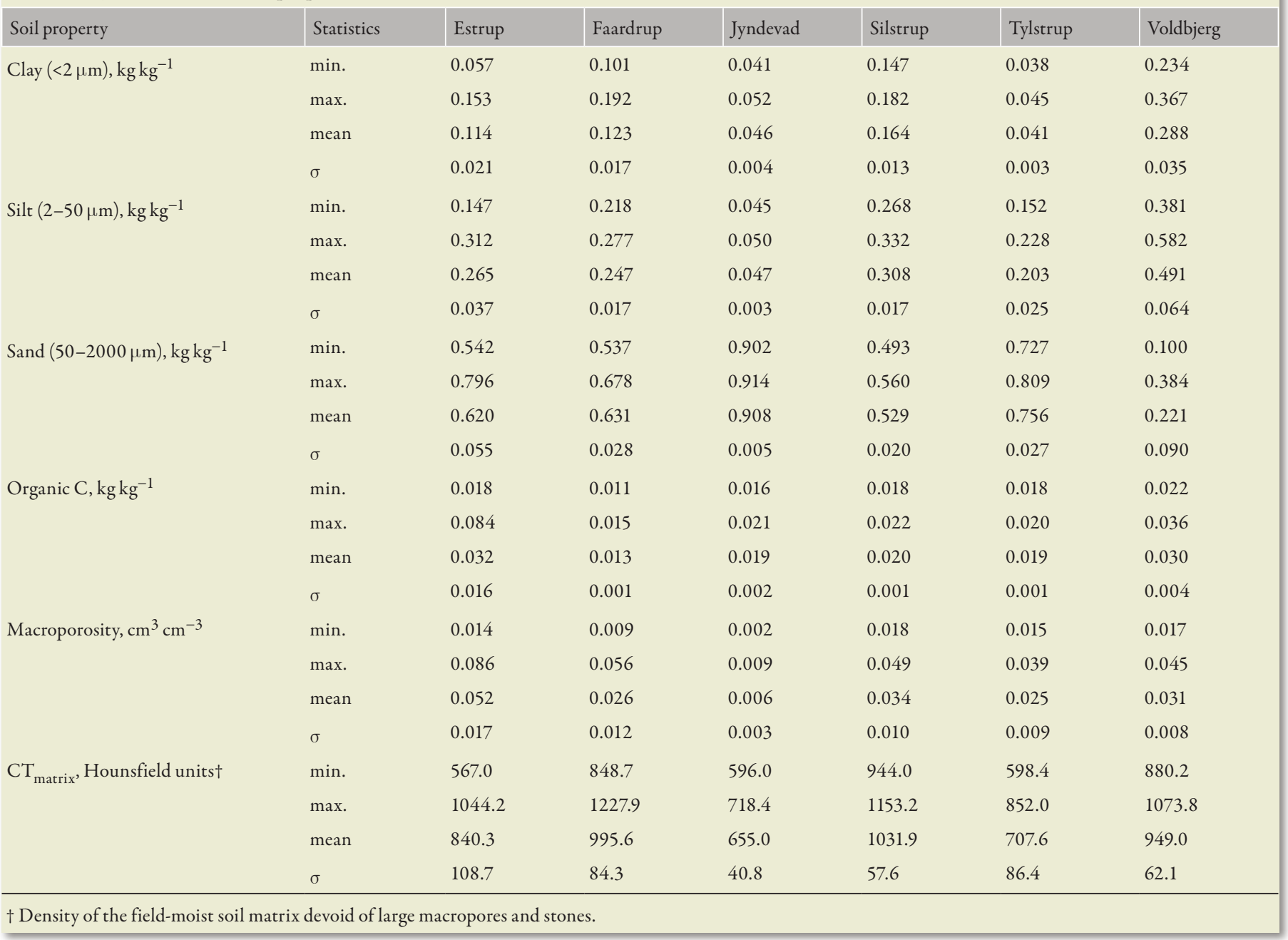

(Tsuchiyama et al., 2000). The 12-bit, signed, reconstructed images obtained from the scanner were calibrated to a range between -1024 and $3071 \mathrm{HU}$ based on daily calibration of pure water, which was set to $0 \mathrm{HU}$. The images were processed and analyzed using ImageJ software, Version 1.47h (Ferreira and Rasband, 2012). Preprocessing of the CT images was performed to untilt and crop the images. The images were converted to 8 -bit gray-scale images and segmented using the algorithm proposed by Sauvola and Pietikäinen (2000). Post-processing included denoising the binary images by removing dubious features $<1.2 \mathrm{~mm}$ in diameter. This resulted in rendering pores $(\geq 1.2 \mathrm{~mm})$ as white objects and the background as black in the binary images. Macroporosity $\left(\mathrm{cm}^{3} \mathrm{~cm}^{-3}\right)$ of the soil columns was calculated, using the filtered binary images, as the volume of pores to the total volume of the soil cores. In addition to segmentation of the pore features, stones were also segmented by fitting a second-order polynomial in the image histogram corresponding to dense fractions $(>1000 \mathrm{HU})$ and selecting the minimal point in the polynomial as the threshold for segmenting stones. The $\mathrm{CT}_{\text {matrix }}(\mathrm{HU})$ was determined as described by Katuwal et al. (2015b). Briefly, segmented pore networks and stones were masked in the original 12-bit signed images, and the average $\mathrm{CT}$ number $(\mathrm{HU})$ of the remaining voxels was calculated to determine the $\mathrm{CT}$ number of the matrix $\left(\mathrm{CT}_{\text {matrix }}\right)$. Because the CT number of the voxels is affected by the electron density and bulk density of the materials within the voxels and the energy of the X-rays (Anderson et al., 1988), variations in the $\mathrm{CT}_{\text {matrix }}$ of soils scanned under identical energy settings are accountable to variations in both bulk density and soil-moisture content. The soils studied were scanned under field-moist conditions, at which they were expected to be close to field capacity, yet precise information on the matric potential of the soils under field-moist conditions was not available. Variations in $\mathrm{CT}_{\text {matrix }}$ in the studied soils could partly be due to variations in the matric potential at the time of scanning.

\section{Visible-Near-Infrared Measurements and Analyses}

Bulk soils collected from the top $20 \mathrm{~cm}$ at each sampling point were air dried, crushed, and sieved through $2 \mathrm{~mm}$. Stones and plant residues were removed prior to crushing of the soils. After thoroughly mixing, about 30 to $50 \mathrm{~g}$ of soil was scanned with a vis-NIR spectrometer (DS2500, Foss) in the spectral range from 400 to 
$2500 \mathrm{~nm}$ at a resolution of $0.5 \mathrm{~nm}$. The soil was placed in a rotating sample cup (7-cm diameter), which was scanned four times at seven different points and averaged. An instrument quality-check procedure, including scanning a white reference, was performed before initiation of spectral measurements. The equipment measures the reflectance $(R)$ of the soil samples, and subsequently converts $R$ to absorbance $A[=\log (1 / R)]$.

Statistical analyses of the spectral data were performed using the PLS Toolbox 8.0 software (Eigenvector Research Inc.). First, principal component analysis (PCA) was performed for classifying the soils' vis-NIR spectra, and later partial least squares regression (PLSR) was performed for the estimation of soil texture (clay, silt, and sand), OC, and the soil structure parameters (macroporosity and $\left.\mathrm{CT}_{\text {matrix }}\right)$. The PCA was performed on the raw vis-NIR absorbance spectra for all the soils. The raw absorbance data were plotted in the principal component spaces for identifying the spectral similarity-dissimilarity among the soils (Martens and Næs, 1989). The relationship between the spectral wavelengths and the principal components was also assessed.

Partial least squares regression is a popular method for analyzing spectroscopic data, using a data compression technique to compress the highly collinear predictor variables (spectral wavelengths) to a few orthogonal factors. It then uses those successive orthogonal factors to develop a predictive linear model that maximizes the covariance between the spectra and the measured soil property (Martens and Næs, 1989; Wold et al., 2001). The PLSR was performed on the preprocessed spectra. Preprocessing of the spectral data is essential to remove noise due to light scatter, correct for baseline shifts, and enhance and extract spectral features for the development of predictive models (Nawar et al., 2016; Rinnan et al., 2009). However, the performance of the preprocessing methods for the predictive ability of a model can depend on the properties of the data sets used (heterogeneity of soil properties) but also on instrumentation (Knadel et al., 2013a; Nawar et al., 2016; Nocita et al., 2014). The second derivative (with segment $=21$, i.e., smoothing of the raw spectral data by averaging across 21 data points; and gap $=7$, i.e., derivatives taken with a gap size of 7 between segments of smoothed points) (Norris, 2001) was used as a pretreatment method for baseline correction and for enhancing weak signals in the spectra. The PLSR models for the prediction of soil texture, OC, and the soil structure parameters (macroporosity and $\mathrm{CT}_{\text {matrix }}$ ) were first developed for a calibration data set and were then applied to a validation data set. Two-thirds of the total data ( 85 samples) were used for calibration and one-third (42 samples) for validation. The subsets were chosen using the Kennard-Stone algorithm (Kennard and Stone, 1969). A 10-fold random cross-validation was also performed on the calibration data set. The data sets used for the validation set were not spatially independent but were derived from within the field sites studied, with soil properties similar to those used for the calibration model. Such a strategy can result in overestimation of the predictive performance of the model (Brown et al., 2005).

The optimum number of components (factors) to be included in the PLSR model was based on the variation in the root mean squared error values for calibration (RMSEC) and cross-validation (RMSECV) with the different numbers of factors (Fig. 2). The number of factors that resulted in both the smallest RMSECV and also the smallest difference between the RMSEC and RMSECV was used in the final model. The PLSR coefficients were also derived and used for identifying the wavelengths important for the prediction of soil texture, OC, macroporosity, and $\mathrm{CT}_{\text {matrix}}$.

\section{Multiple Linear Regressions}

In a comparison with the vis-NIR-PLSR-based statistical predictions, macroporosity and $\mathrm{CT}_{\text {matrix }}$ were also estimated for the same set of validation data as used in PLSR using multiple linear regression (MLR) developed for the calibration data set using soil texture and OC. The best subset procedure was performed to select the subset of independent variables (clay, silt, sand, and OC) with the highest predictive power for the MLR. In this procedure, multiple linear regressions are performed systematically with different combinations of the independent variables, and the subset of the variables that best predicts the dependent variable is selected. The best subset is selected by comparing $R^{2}$, adjusted $R^{2}$, and the total squared error (Mallows's $C_{\mathrm{p}}$ ) (Hocking, 1976). Multicollinearity, due to intercorrelated independent variables in the derived regression function, was avoided by not including the variables with a high variance inflation factor (Kutner et al., 2005).

\section{Statistics}

The performance of the models was assessed with the root mean square error (RMSE) and the coefficient of determination, $R^{2}$,

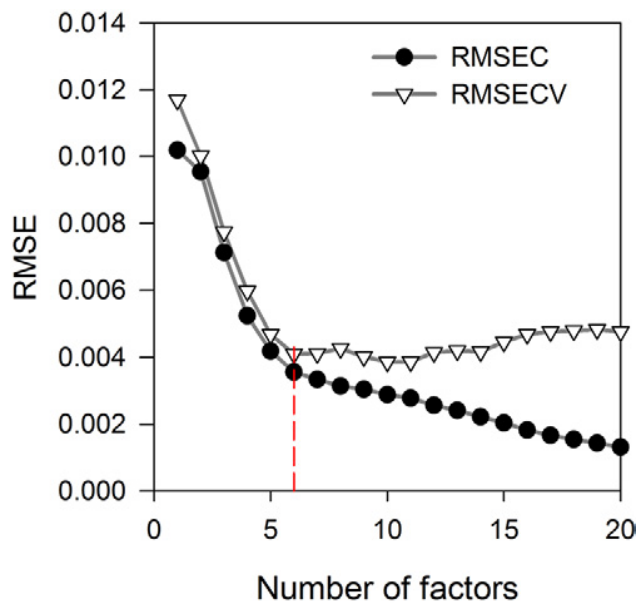

Fig. 2. Variation in root mean square error (RMSE) for the prediction of organic $\mathrm{C}\left(\mathrm{kg} \mathrm{kg}^{-1}\right)$ with the number of factors included in prediction models (RMSEC, root mean square error of calibration; RMSECV, root mean square error of cross-validation). The broken red line indicates the number of factors resulting in the smallest RMSECV and the smallest difference between RMSE and RMSECV. 
between the measured and predicted soil properties. The ratio of performance to deviation (RPD) was calculated as the ratio of the standard deviation to the RMSE (Chang and Laird, 2002), and the ratio of performance to interquartile distance (RPIQ) was calculated as the ratio of the interquartile distance to the RMSE (Bellon-Maurel et al., 2010) to assess the predictive strength of the models.

\section{Results and Discussion}

\section{Soil Physical and Structural Properties}

The agricultural fields selected in the study (Fig. 1) had different characteristics in terms of soil texture and OC content (Table 1). The clay content of the soils studied ranged between 0.038 and $0.367 \mathrm{~kg} \mathrm{~kg}^{-1}$ and the soil OC between 0.011 and $0.084 \mathrm{~kg} \mathrm{~kg}^{-1}$. The highest clay contents were found in the Voldbjerg soils ( $0.234-$ $\left.0.367 \mathrm{~kg} \mathrm{~kg}^{-1}\right)$. The Estrup field presented a large gradient in OC $\left(0.018-0.084 \mathrm{~kg} \mathrm{~kg}^{-1}\right)$, whereas the Tylstrup and Jyndevad sites were dominated by coarse fractions in the topsoil (sand $>0.727 \mathrm{~kg}$ $\mathrm{kg}^{-1}$ ). Although similar in texture, the topsoil at the Silstrup site had higher clay and OC contents than the Faardrup site. The effect of the variation in the texture and $\mathrm{OC}$ among the fields was clearly observed in the spectral absorbance (Fig. 3a), explained below.

Large variations in the soil structural properties (macroporosity and $\mathrm{CT}_{\text {matrix }}$ ) were also present, with the largest macroporosity observed at Estrup and the lowest at Jyndevad. The macropores in the fields were highly variable in both quantity and other characteristics such as number, size distribution, and connectivity (data not shown), which can visually be assessed in Fig. $3 \mathrm{~b}$. The $\mathrm{CT}_{\text {matrix }}$ was positively correlated with clay content $(r=0.58)$ and negatively correlated with OC $(r=-0.39)$. Weaker correlations were obtained between macroporosity and the texture (clay, silt, and sand) and OC content compared with $\mathrm{CT}_{\text {matrix }}$. The strongest correlation of macroporosity was with OC, which was 0.37 (Table 2). Macroporosity, or structural porosity, in soil consists of cracks, biopores, and macrostructures and is influenced by various factors such as soil physical properties, climate, and management practices such as tillage, compaction, and cropping and their interactions (Dexter, 2004). Thus, macroporosity has a lower 1:1 correlation with the soil properties.

\section{Spectral Properties}

The average spectral absorbance for each field is shown in Fig. 3a, and the corresponding second derivative of the spectra is shown in Fig. 4. The spectra for the soils showed high absorption in the visible region, prominent absorption peaks around 1400, 1900, and $2200 \mathrm{~nm}$ in the infrared region, and a few small peaks between 2300 and $2500 \mathrm{~nm}$. Absorptions in the visible range (400-700 $\mathrm{nm}$ ) are generally due to organic matter, Fe oxides, and the color of the soil. In the NIR range ( $700-2500 \mathrm{~nm}$ ) the absorption peaks around 1400 and $1900 \mathrm{~nm}$ are associated with the $\mathrm{OH}$ functional

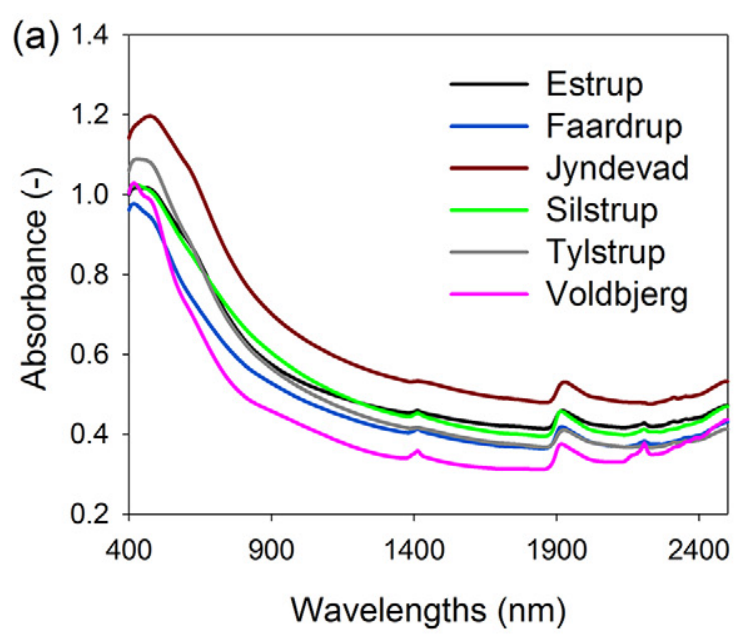

(b) Estrup
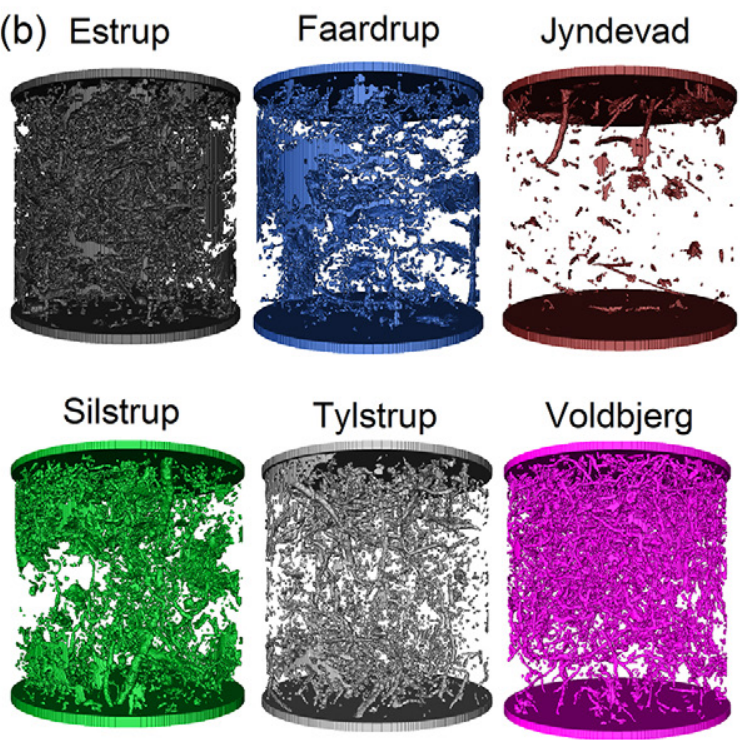

Voldbjerg

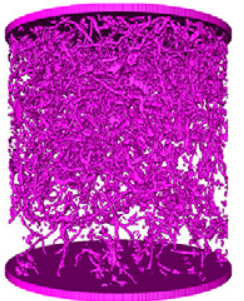

Fig. 3. (a) Average spectral responses in the visible-near-infrared region by soils from different fields and (b) three-dimensional renderings of macropores of representative soil columns from each field.

group of free water, and at $2200 \mathrm{~nm}$ with the $\mathrm{OH}$ functional group of the clay lattice (Ben-Dor and Banin, 1995; Shepherd and Walsh, 2002).The difference in the soil properties of the fields (soil color, OC, and particle size) was clearly reflected in the overall spectral absorbance of the fields. Only a minimal effect of clay mineralogy

Table 2. Spearman's rank correlation coefficient between different soil properties.

\begin{tabular}{lllllll} 
Property & Silt & Sand & Organic C & Macroporosity & $\mathrm{CT}_{\text {matrix }}{ }^{\dagger}$ \\
Clay & $0.86^{* * *}$ & $-0.94^{* * *}$ & $0.23^{* *}$ & 0.16 & $0.58^{* * *}$ \\
Silt & & $-0.97^{* * *}$ & $0.52^{* * *}$ & $0.29^{* *}$ & $0.35^{* * *}$ \\
Sand & & & $-0.41^{* * *}$ & $-0.25^{* *}$ & $-0.45^{* * *}$ \\
Organic C & & & & $0.37^{* * *}$ & $-0.39^{* * *}$ \\
Macroporosity & & & & & -0.16 \\
\hline
\end{tabular}

** Significant correlation at the 0.01 probability level.

*** Significant correlation at the 0.001 probability level.

† Density of the field-moist soil matrix devoid of large macropores and stones. 
should be present in the spectral reflectance of the studied soils because most Danish soils have illite as the dominant clay mineral (Møberg et al., 1988). Moisture level did not affect the measurement because the soils were air dried before vis-NIR measurements. The $\mathrm{OH}$ peaks (peaks around 1400, 1900, and $2200 \mathrm{~nm}$ ) were more prominent in the soils from Voldbjerg, where the clay content is high, and less prominent for Jyndevad and Tylstrup with low clay contents (Fig. 4). Organic matter in soil absorbs electromagnetic radiation in the visible range due to electronic absorption and increases the darkness of the soil color, resulting in a higher absorbance (Bartholomeus et al., 2008; Chang and Laird, 2002). Despite the higher OC contents of the Estrup soils, the spectra of the Jyndevad soils had higher absorbance for all wavelengths (Fig. 3a). The high absorbance in the Jyndevad soils could be because the smaller surface area and large spacing between the particles in a coarse-textured soil can result in large scatter of the radiation and less reflectance (high absorbance) (Clark, 1999; Mouazen et al., 2005). Moreover, the smaller surface area can also result in a thicker OC coating layer compared with finer textured soil

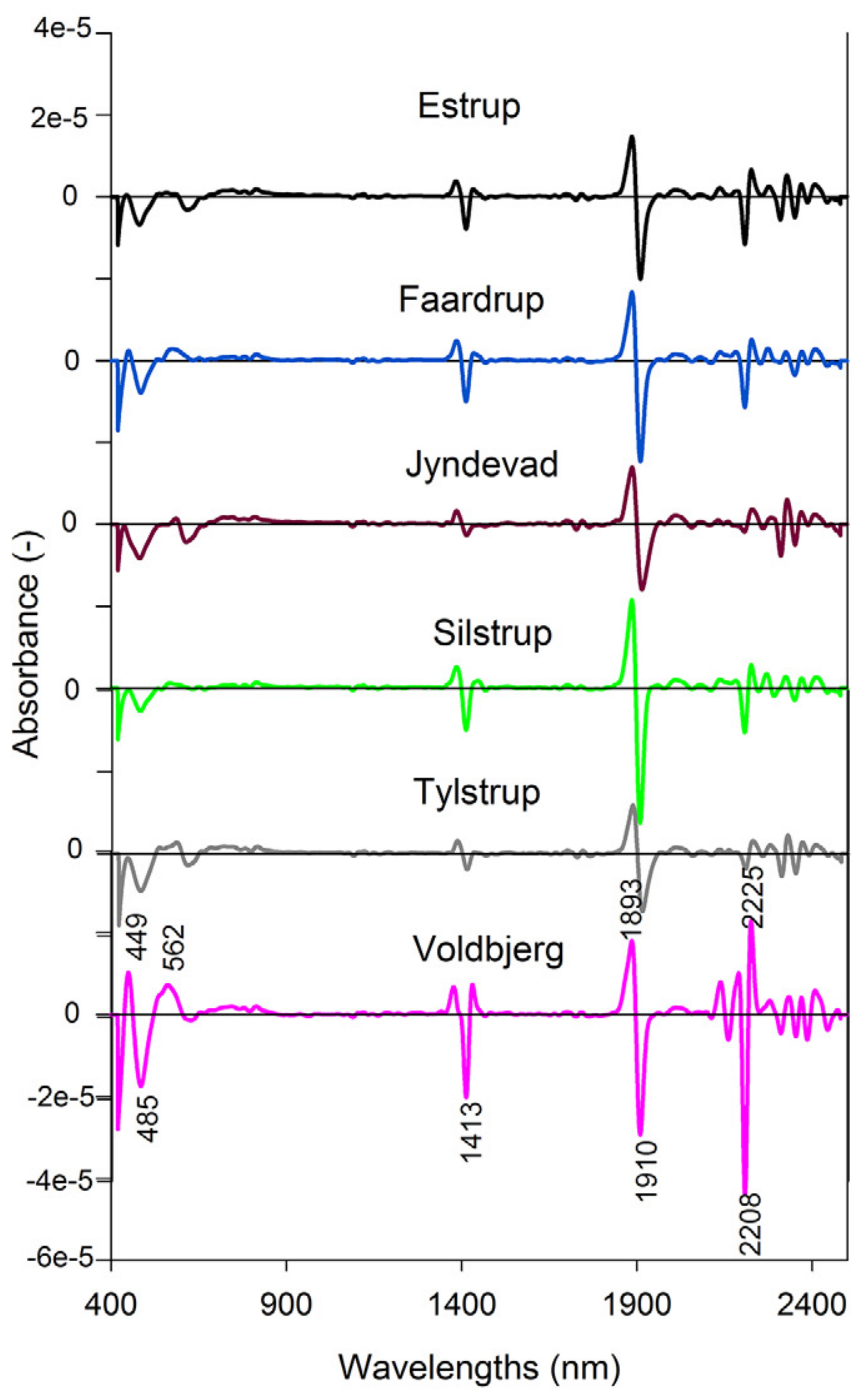

Fig. 4. Average spectral responses for each field after preprocessing using gap segment second derivative.
(Stenberg et al., 2010), resulting in higher absorption in the visible range. However, OC in the Jyndevad soil was present loosely and not bound to soil particles, giving it a darker color than the other soils. The overall low absorbance for the Voldbjerg soils (Fig. 3a) could be associated with the higher clay content in the soils and corresponds to the findings of Bilgili et al. (2010).

The results of the PCA of the raw absorbance spectra are shown in Fig. 5. The first two principal components (PCs) explained about $97 \%$ of the total variance in the spectral data. The soils were generally grouped together in the principal component space according to field site (Fig. 5a), clearly illustrating the influence of variations in soil properties among the field sites on the spectral features of the soils. Voldbjerg and Jyndevad sites, representing the soils with the most clay and sand, respectively, were clustered in two separate groups on the negative and the positive parts of the $\mathrm{PC} 1$ axis, respectively. Even though the Jyndevad site was a homogeneous field, the soils were highly scattered along PC2 (explaining 5\% of the variability in the spectra) (Fig. 5a). This may be due to the bias in the selection of the soil samples, as soil samples with large variations in clay and $\mathrm{OC}$ content were intentionally chosen to represent the variability in the field plot. In the PC scores plot (Fig. 5a), Faardrup and Silstrup soils overlap with the soils from the Estrup
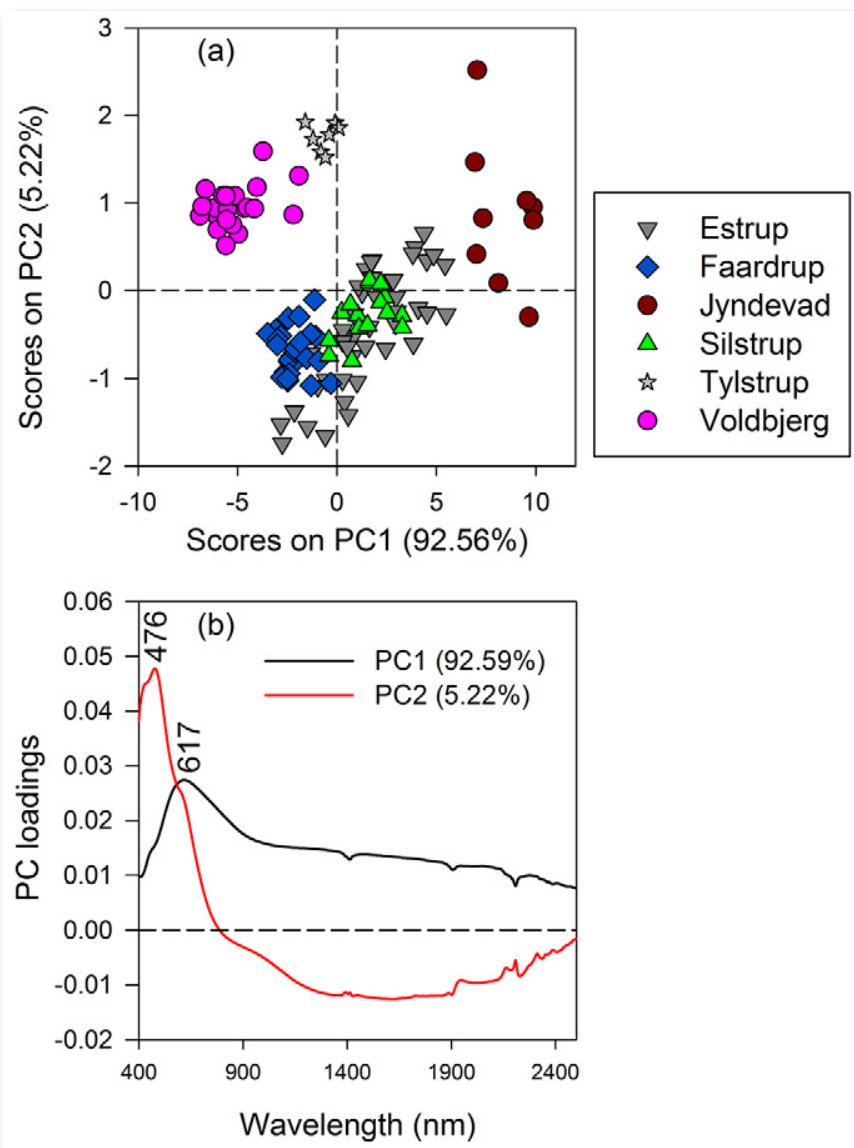

Fig. 5. Principal component (PC) analysis of the visible-near-infrared spectra of the soils with (a) the score plots of the first two principle components and (b) their loadings at different wavelengths. 
site, which had the highest gradient in soil OC. Estrup soils are relatively scattered along a $45^{\circ}$ line between the PC1 and PC2 axes (Fig. 5a), which could indicate a joint effect of the two PCs on the sample distribution for this data set. The first component explained $93 \%$ of the variance, and its highest loadings were within the visible region, with a peak at $617 \mathrm{~nm}$ (Fig. 5b). This region has previously been identified as where absorptions related to organic matter take place (Galvao and Vitorello, 1998), indicating that the majority of the variation within $\mathrm{PCl}$ was driven by the amount or the quality of organic matter present at the field sites. The highest loading for PC2 was found at $476 \mathrm{~nm}$ and was related to the presence of Fe oxides (Hunt, 1977), indicating that the scatter among the Jyndevad samples can be attributed to the differences in Fe oxides in the sandy fraction at this site. The high variation in the Estrup samples can be attributed to both the effect of organic matter and the presence of Fe oxides.

\section{Prediction of Texture and Organic Carbon}

The results of PLSR analysis of texture and OC for the calibration and validation data sets are presented in Fig. 6 (left), with the performance of the models summarized in Table 3. The regression coefficients (Fig. 6, right) describe the importance of the wavelengths for the prediction of the variables using PLSR models. The optimum number of factors for developing the prediction models for texture and OC was between three and six. The texture (clay, silt, and sand) and OC were well predicted using vis-NIR spectroscopy, with $R^{2}$ ranging between 0.87 and $0.96, \mathrm{RPD}$ between 2.5 and 3.6, and RPIQ between 1.6 and 4.9 for the validation data set (Table 3 ). Significant peaks located in the visible range, and more prominently in the NIR region around 1413,1907 , and $2208 \mathrm{~nm}$, were present for all the predicted soil properties. Clay and OC contents are the soil physical properties most commonly well predicted with the vis-NIR method because of their specific spectral signatures in the vis-NIR range.

The wavelengths contributing most to the prediction of clay content were found at 419, 452, 611, 1413, 1907, 2208, 2225, 2307, and $2329 \mathrm{~nm}$ (Fig. 6b). Bilgili et al. (2010) obtained the highest
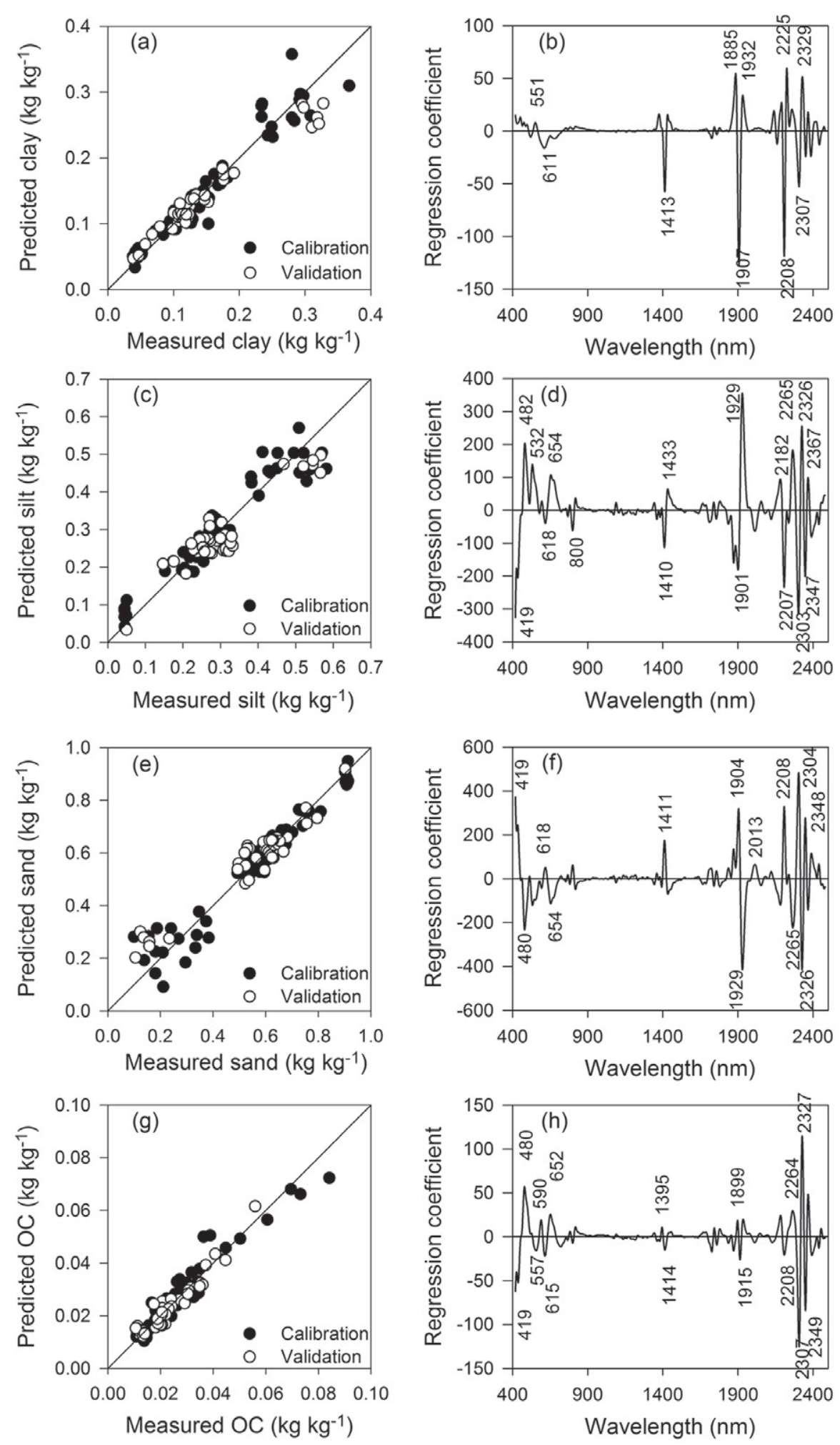

Fig. 6. Prediction of various soil physical properties (left) and the regression coefficients between the predicted variables and wavelength (right). correlation for soil clay content at $450 \mathrm{~nm}$, whereas Islam et al. (2003) reported the most significant wavelengths at 1901 and 1912 $\mathrm{nm}$. Clay mineralogy and Fe oxides largely influence the absorption features in the vis-NIR spectrum (Stenberg et al., 2010). The 
Table 3. Statistics of the calibration and validation results for soil properties, including the coefficient of determination $\left(R^{2}\right)$, root mean square error (RMSE), ratio of performance to deviation (RPD), and ratio of performance to interquartile distance (RPIQ).

\begin{tabular}{|c|c|c|c|c|c|c|c|c|c|}
\hline \multirow[b]{2}{*}{ Soil property } & \multirow[b]{2}{*}{ Factors } & \multicolumn{4}{|c|}{ 10-fold cross-validation } & \multicolumn{4}{|c|}{ Prediction } \\
\hline & & $R^{2}$ & RMSE & RPD & RPIQ & $R^{2}$ & RMSE & RPD & RPIQ \\
\hline Clay & 3 & 0.92 & 0.022 & 3.5 & 2.8 & 0.96 & 0.021 & 3.6 & 2.8 \\
\hline Silt & 4 & 0.88 & 0.042 & 2.9 & 1.8 & 0.87 & 0.045 & 2.5 & 1.6 \\
\hline Sand & 4 & 0.92 & 0.054 & 3.6 & 2.2 & 0.93 & 0.059 & 3.1 & 1.9 \\
\hline Organic C & 6 & 0.90 & 0.004 & 3.2 & 2.4 & 0.92 & 0.003 & 3.5 & 4.9 \\
\hline
\end{tabular}

characteristic features at 1400 and $1900 \mathrm{~nm}$ are attributed to the $\mathrm{OH}$ groups of soil moisture and that at $2200 \mathrm{~nm}$ is characteristic of the crystal lattice $(\mathrm{Al}-\mathrm{OH})$ in soil clay minerals. Knadel et al. (2013b) reported strong absorbance at $2206 \mathrm{~nm}$, in addition to 1400 and $1900 \mathrm{~nm}$, for Danish soils and particularly for clayey soils, which is associated with the dominance of illite in the clay fraction. Illite, which dominates the clay in these soils, also has weaker signatures near 2300 and $2400 \mathrm{~nm}$ (Clark, 1999).

Although there has been a lot of research on texture, the silt and sand fractions have gained less attention for spectroscopic predictions. No specific absorption features can be directly related to the silt fraction (Curcio et al., 2013). The predictions of both silt and sand content were better than what has mostly been reported (Bilgili et al., 2010; Curcio et al., 2013; Islam et al., 2003; Sørensen and Dalsgaard, 2005; Viscarra Rossel et al., 2016), with an $R^{2}$ of 0.87 and 0.93 and RMSE of 0.045 and $0.059 \mathrm{~kg} \mathrm{~kg}^{-1}$, respectively (Table 3). The better prediction of silt and sand in our study could be due to their high correlation with clay content (Table 2). Despite the high correlation among clay, silt, and sand content and the similarity in the plot of regression coefficients, the wavelengths between 2250 and $2500 \mathrm{~nm}$ were found to be more important for the prediction of silt and sand content than for clay.

Six factors were used for the prediction of OC in the study, which resulted in an $R^{2}$ of 0.92 , RMSE of $0.003 \mathrm{~kg} \mathrm{~kg}^{-1}$, RPD of 3.5 , and RPIQ of 4.9 using PLSR (Table 3). For OC prediction, the important wavelengths were found in the visible region (430-620 $\mathrm{nm}$ ) and more prominently in the NIR region between 2200 and $2400 \mathrm{~nm}$. The highest correlations were obtained for wavelengths at 2307, 2327, and $2349 \mathrm{~nm}$ (Fig. 6g-6h). Several spectral bands in the NIR region are related to absorption due to organic matter, with the most prominent ones at 1730, 1760, 2050, and 2300 to $2350 \mathrm{~nm}$ (Ben-Dor et al., 1997; Viscarra Rossel and Behrens, 2010; Stenberg et al., 2010). Absorption features at 2309 and 2347 $\mathrm{nm}$ are related to $\mathrm{C}-\mathrm{H}$ bonds in the organic compounds (humic acids and cellulose) (Ben-Dor et al., 1997). Because of the complex nature of organic matter, with many and varied functional groups absorbing at various wavelengths, it is usually difficult to specifically assign a particular wavelength to a particular response (Ben-Dor and Banin, 1995). Organic C in the literature has been predicted with different degrees of success using visNIR (Viscarra Rossel et al., 2016). Wight et al. (2016) observed that texture heterogeneity can interfere with the predictability of OC. Similar results were reported by Stenberg et al. (2010) on the influence of texture (coarse sand) on the predictability of OC using vis-NIR. The good predictability of OC in this study compared with Wight et al. (2016) and Stenberg et al. (2010) could be because of the narrower textural range of the studied soils than those studies. Different wavelengths have been associated with the prediction of soil OC. While Yang et al. (2012) reported that the inclusion of the visible range between 600 and $760 \mathrm{~nm}$ can improve the prediction of OC contents, Vohland and Emmerling (2011) achieved the most successful OC predictions using wavelengths $>1200 \mathrm{~nm}$, with wavelengths $>2100 \mathrm{~nm}$ in the NIR region being the most significant ones. They further reported that the spectral region $>1900 \mathrm{~nm}$, and in particular the hydroxyl bond at $2200 \mathrm{~nm}$, is of particular importance for the prediction of OC.

\section{Prediction of Soil Structural Properties}

The soil structural properties of macroporosity and $\mathrm{CT}_{\text {matrix }}$ were correlated with texture (sand, silt, and clay fractions) and OC (Table 2). Macroporosity and $\mathrm{CT}_{\text {matrix }}$ were estimated both directly from the texture and OC using MLR and by visNIR spectroscopy using PLSR (vis-NIR-PLSR). Because of the intercorrelation between texture and $\mathrm{OC}$, not all of them were used in the estimation of macroporosity and $\mathrm{CT}_{\text {matix }}$. Using MLR, macroporosity was estimated using silt, sand, and OC, while $\mathrm{CT}_{\text {matrix }}$ was estimated using clay, sand, and OC. Table 4 shows the performance of the two methods in predicting macroporosity and $\mathrm{CT}_{\text {matrix }}$. Macroporosity was predicted poorly, with $R^{2}<0.5$, RPD $<1.4$, and RPIQ $<2$ for the validation data set using both methods. The vis-NIR-PLSR prediction model for macroporosity captured the variation among the different soils but not the variation within the fields (Fig. 7a). The highest regression coefficients for the prediction of macroporosity were associated with wavelengths at 421,452 , and $593 \mathrm{~nm}$ in the visible range and at 1406, 1898, 1924, 2161, 2224, 2302, and $2321 \mathrm{~nm}$ in the NIR range (Fig. 7b). The wavelengths close to 2302 and $2321 \mathrm{~nm}$ were also found to be important for the prediction of silt, sand, and OC content (Fig. 6c-6h). Despite the correlations with $\mathrm{OC}$, the variation in macroporosity with OC in the Estrup soils was not captured with vis-NIR-PLSR (Fig. 7a). Macroporosity, as described in this study, consists of large pore networks $>1.2 \mathrm{~mm}$ and is a highly dynamic soil property affected by various natural and human interventions, such as plant roots and earthworms, and the mechanical disturbance of the soil. The use of soil texture and organic matter alone is thus insufficient for the prediction of macroporosity in soil.

The predictions of $\mathrm{CT}_{\text {matrix }}$ were better than for macroporosity, with higher RPD, RPIQ, and $R^{2}$ values for both methods, and 
Table 4. Prediction performance of multiple linear regression (MLR) and partial least squares regression (PLSR), including the coefficient of determination $\left(R^{2}\right)$, root mean square error (RMSE), ratio of performance to deviation (RPD), and ratio of performance to interquartile distance (RPIQ), for the prediction of soil structural properties.

\begin{tabular}{|c|c|c|c|c|c|c|c|c|c|c|}
\hline \multirow[b]{2}{*}{ Structural property } & \multirow[b]{2}{*}{ Predictors } & \multirow[b]{2}{*}{$N \dagger$} & \multicolumn{4}{|c|}{ Calibration/cross-validation $\neq$} & \multicolumn{4}{|c|}{ Validation } \\
\hline & & & $R^{2}$ & RMSE & RPD & RPIQ & $R^{2}$ & RMSE & RPD & RPIQ \\
\hline \multirow[t]{2}{*}{$\begin{array}{l}\text { Macroporosity } \\
\left(\mathrm{cm}^{3} \mathrm{~cm}^{-3}\right)\end{array}$} & $\begin{array}{l}\text { Soil properties, MLR } \\
\text { (silt, sand, organic C) }\end{array}$ & 3 & 0.44 & 0.015 & 1.3 & 2.0 & 0.26 & 0.015 & 1.1 & 1.5 \\
\hline & vis-NIR-PLSR & 4 & 0.54 & 0.013 & 1.5 & 1.8 & 0.40 & 0.013 & 1.2 & 1.7 \\
\hline $\begin{array}{l}\mathrm{CT}_{\text {matrix }} \\
\text { (Hounsfield units) } \$\end{array}$ & $\begin{array}{l}\text { Soil properties, MLR } \\
\text { (clay, sand, organic C) }\end{array}$ & 3 & 0.77 & 67.4 & 2.1 & 2.7 & 0.66 & 78.8 & 1.6 & 2.0 \\
\hline
\end{tabular}

† Number of factors used in the models.

₹ The parameters for calibration are for MLR, whereas cross-validation refers to vis-NIR-PLSR.

$\S$ Density of the field-moist soil matrix devoid of large macropores and stones.

with vis-NIR-PLSR producing better results than MLR on soil properties (Fig. 7a-7d; Table 4). Similar results were obtained by Santra et al. (2009), who found that vis-NIR spectroscopy can produce prediction results for soil hydraulic properties that are comparable or even better than those obtained using pedotransfer functions based on basic soil properties. This could be because vis-NIR spectra are affected by clay mineralogy and the properties of organic matter (Stenberg et al., 2010), which were not included in the pedotransfer functions (MLR) in the study. The wavelengths contributing most to the prediction model of $\mathrm{CT}_{\text {matrix }}$ using vis-NIR-PLSR were found in the visible range (maximum at 451 and $611 \mathrm{~nm}$ ), 1409 and 1905 (which are close to the water absorption features), and wavelengths between 2160 and $2400 \mathrm{~nm}$ in the NIR range (Fig. 7 d). These wavelengths were also highly correlated with clay, silt, sand, and OC (Fig. 6a-6h). For soils of similar mineralogical composition, $\mathrm{CT}_{\text {matrix }}$ represents the density of the moist soil matrix excluding the macropores and stones and is affected by various factors such as mechanical disturbance of the soil and the degree of soil aggregation and compactness. The fields were not plowed for at least a year before sampling and were under similar management practices. The variation in $\mathrm{CT}_{\text {matrix }}$ could be due to the differences in the extent of aggregate formation and stabilization, which are, in turn, closely affected by soil texture and OC (Horn et al., 1994), and partly due to variations in soil matric potential during scanning. The successful prediction of $\mathrm{CT}_{\text {matrix }}$ is attributable to its correlation with texture and OC content.
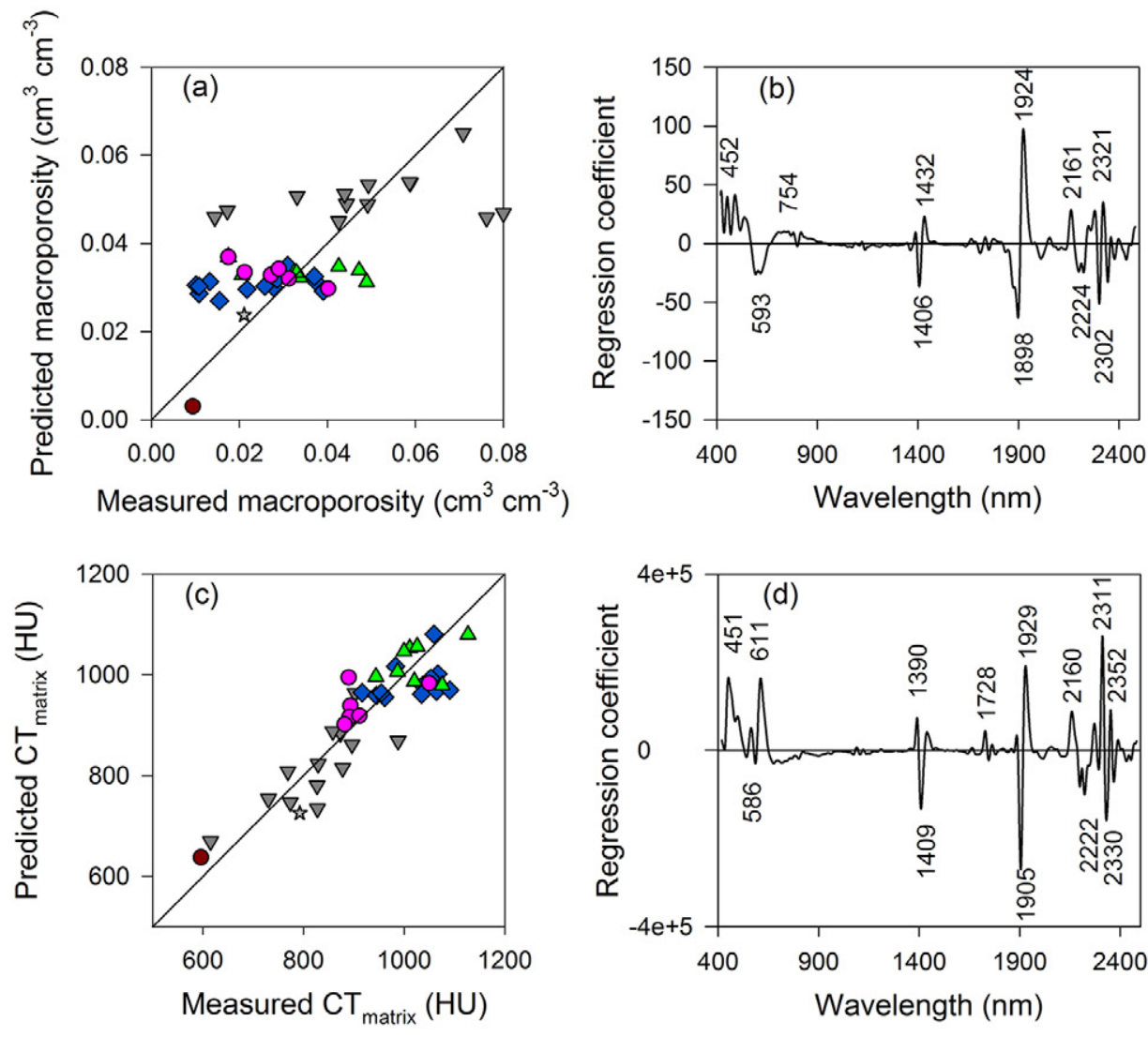

Fig. 7. (a,c) Prediction of soil structural properties (macroporosity and the density of the field-moist soil matrix devoid of large macropores and stones $\left.\left[\mathrm{CT}_{\text {matrix }}\right]\right)$ and $(\mathrm{b}, \mathrm{d})$ the regression coefficients between the predicted variables and wavelengths. 


\section{Conclusions}

This study aimed at using a rapid method, vis-NIR spectroscopy, for the prediction of soil structural properties obtained from X-ray CT scanning. Undisturbed soils from six agricultural fields within Denmark with varying texture and $\mathrm{OC}$ contents were scanned and analyzed for macroporosity and $\mathrm{CT}_{\text {matrix }}$ (field-moist matrix bulk density) using X-ray CT scanning. Macroporosity and $\mathrm{CT}_{\text {matrix }}$ along with soil texture and OC, were predicted using vis-NIR spectroscopy and PLSR on disturbed soil that had been crushed and air dried from the same points in the six fields. In addition to using vis-NIR-PLSR, prediction of macroporosity and CT $\mathrm{T}_{\text {matrix }}$ were also done using MLR on texture and OC.

Considerable differences in absorption features of the vis-NIR spectra were observed among the fields, and the soils were grouped by fields based on the vis-NIR spectra. The differences in the spectra for the six fields were related to the differences in the physical constituents (clay, silt, sand, and OC). Despite the differences, significant spectral absorption features were similar for all the fields, with prominent features at 1413, 1910, and $2208 \mathrm{~nm}$. Clay, silt, sand, and OC were successfully predicted using vis-NIR-PLSR $\left(R^{2}>0.85\right.$, RPD $>2.5$, and RPIQ $\left.>1.5\right)$. The prediction of macroporosity was poor with both vis-NIR-PLSR and MLR. The $\mathrm{CT}_{\text {matrix }}$ was predicted well with both methods, with vis-NIR producing better results than using the soil properties, suggesting that vis-NIR spectroscopy could be an easier, faster, and more economic means of predicting $\mathrm{CT}_{\text {matrix }}$ values than using texture and OC. The good prediction of soil properties and $\mathrm{CT}_{\text {matrix }}$ by vis-NIR in this study also indicates that a potential application of vis-NIR spectroscopy could be the prediction of soil hydraulic properties and preferential flow and transport, which is a part of ongoing research.

\section{Acknowledgments}

This research was funded by an Aarhus University Research Foundation grant (AUFFE-2016-9-36) and a research grant (13162) from VILLUM FONDEN. We are grateful to the editors and the two anonymous reviewers for their helpful comments and suggestions.

\section{References}

Al-Raoush, R.I., and C.S. Willson. 2005. Extraction of physically realistic pore network properties from three-dimensional synchrotron X-ray microtomography images of unconsolidated porous media systems. J. Hydrol. 300:44-64. doi:10.1016/j.jhydrol.2004.05.005

Anderson, S.H. 2014. Tomography-measured macropore parameters to estimate hydraulic properties of porous media. Procedia Comput. Sci. 36:649-654. doi:10.1016/j.procs.2014.09.069

Anderson, S.H., C.J. Gantzer, J.M. Boone, and R.J. Tully. 1988. Rapid nondestructive bulk density and soil-water content determination by computed tomography. Soil Sci. Soc. Am. J. 52:35-40. doi:10.2136/sssaj1988.03615995005200010006x

Askari, M.S., J. Cui, S.M. O'Rourke, and N.M. Holden. 2015. Evaluation of soil structural quality using VIS-NIR spectra. Soil Tillage Res. 146:108117. doi:10.1016/j.still.2014.03.006

Babaeian, E., M. Homaee, C. Montzka, H. Vereecken and A.A. Norouzi. 2015a. Towards retrieving soil hydraulic properties by hyperspectral remote sensing. Vadose Zone J. 14(3). doi:10.2136/vzj2014.07.0080.

Babaeian, E., M. Homaee, H. Vereecken, C. Montzka, A.A. Norouzi and M.Th. van Genuchten. 2015b. A comparative study of multiple approaches for predicting the soil-water retention curve:
Hyperspectral information vs. basic soil properties. Soil Sci. Soc. Am. J. 79:1043-1058. doi:10.2136/sssaj2014.09.0355

Bartholomeus, H.M., M.E. Schaepman, L. Kooistra, A. Stevens, W.B. Hoogmoed, and O.S.P. Spaargaren. 2008. Spectral reflectance based indices for soil organic carbon quantification. Geoderma 145:28-36. doi:10.1016/j.geoderma.2008.01.010

Bellon-Maurel, V., E. Fernandez-Ahumada, B. Palagos, J.-M. Roger, and A. McBratney. 2010. Critical review of chemometric indicators commonly used for assessing the quality of the prediction of soil attributes by NIR spectroscopy. TrAC, Trends Anal. Chem. 29:10731081. doi:10.1016/j.trac.2010.05.006

Ben-Dor, E., and A. Banin. 1995. Near-infrared analysis as a rapid method to simultaneously evaluate several soil properties. Soil Sci. Soc. Am. J. 59. doi:10.2136/sssaj1995.03615995005900020014x

Ben-Dor, E., Y. Inbar, and Y. Chen. 1997. The reflectance spectra of organic matter in the visible near-infrared and short wave infrared region (400-2500 nm) during a controlled decomposition process. Remote Sens. Environ. 61:1-15. doi:10.1016/S0034-4257(96)00120-4

Bilgili, A.V., H.M. van Es, F. Akbas, A. Durak, and W.D. Hively. 2010. Visible-near infrared reflectance spectroscopy for assessment of soil properties in a semi-arid area of Turkey. J. Arid Environ. 74:229-238. doi:10.1016/j.jaridenv.2009.08.011

Børgesen, C.D., B.V. Iversen, O.H. Jacobsen, and M.G. Schaap. 2008. Pedotransfer functions estimating soil hydraulic properties using different soil parameters. Hydrol. Processes 22:1630-1639. doi:10.1002/hyp.6731

Bronick, C.J., and R. Lal. 2005. Soil structure and management: A review. Geoderma 124:3-22. doi:10.1016/j.geoderma.2004.03.005

Brown, D.J., R.S. Bricklemyer, and P.R. Miller. 2005. Validation requirements for diffuse reflectance soil characterization models with a case study of VNIR soil C prediction in Montana. Geoderma 129:251-267. doi:10.1016/j.geoderma.2005.01.001

Brown, D.J., K.D. Shepherd, M.G. Walsh, M.D. Mays, and T.G. Reinsch. 2006. Global soil characterization with VNIR diffuse reflectance spectroscopy. Geoderma 132:273-290. doi:10.1016/j.geoderma.2005.04.025

Cambou, A., R. Cardinael, E. Kouakoua, M. Villeneuve, C. Durand, and B.G. Barthès. 2016. Prediction of soil organic carbon stock using visible and near infrared reflectance spectroscopy (VNIRS) in the field. Geoderma 261:151-159. doi:10.1016/j.geoderma.2015.07.007

Cécillon, L., B.G. Barthès, C. Gomez, D. Ertlen, V. Genot, M. Hedde, et al. 2009. Assessment and monitoring of soil quality using nearinfrared reflectance spectroscopy (NIRS). Eur. J. Soil Sci. 60:770-784. doi:10.1111/j.1365-2389.2009.01178.x

Chang, C.-W., and D.A. Laird. 2002. Near-infrared reflectance spectroscopic analysis of soil C and N. Soil Sci. 167:110-116. doi:10.1097/00010694-200202000-00003

Clark, R.N. 1999. Spectroscopy of rocks and minerals, and principles of spectroscopy. In: A.N. Rencz, editor, Remote sensing for the earth sciences: Manual of remote sensing. John Wiley \& Sons, New York. p. 3-58.

Cnudde, V., and M.N. Boone. 2013. High-resolution X-ray computed tomography in geosciences: $A$ review of the current technology and applications. Earth Sci. Rev. 123:1-17. doi:10.1016/j.earscirev.2013.04.003

Curcio, D., G. Ciraolo, F. D'Asaro, and M. Minacapilli. 2013. Prediction of soil texture distributions using VNIR-SWIR reflectance spectroscopy. Procedia Environ. Sci. 19:494-503. doi:10.1016/j.proenv.2013.06.056

Dexter, A.R. 2004. Soil physical quality. I: Theory, effects of soil texture, density, and organic matter, and effects on root growth. Geoderma 120:201-214. doi:10.1016/j.geoderma.2003.09.004

Du, C., and J. Zhou. 2008. Evaluation of soil fertility using infrared spectroscopy: A review. Environ. Chem. Lett. 7:97-113. doi:10.1007/ s10311-008-0166-X

Ferreira, T., and W. Rasband. 2012. ImageJ User Guide, IJc1.46r. Natl. Inst. of Health, Bethesda, MD.

Galvao, L.S., and I. Vitorello. 1998. Role of organic matter in obliterating the effects of iron on spectral reflectance and colour of Brazilian tropical soils. Int. J. Remote Sens. 19:1969-1979. doi:10.1080/014311698215090

Gee, G.W., and D. Or. 2002. Particle-size analysis. In: J.H. Dane and G.C. Topp, editors, Methods of soil analysis. Part 4. Physical methods. SSSA Book Ser. 5. SSSA, Madison, WI. p. 255-293. doi:10.2136/sssabookser5.4.c12

Gomez, C., Y. Le Bissonnais, M. Annabi, H. Bahri, and D. Raclot. 2013. Laboratory Vis-NIR spectroscopy as an alternative method for estimating the soil aggregate stability indexes of Mediterranean soils. Geoderma 209-210:86-97. doi:10.1016/j.geoderma.2013.06.002 
Helliwell, J.R., C.J. Sturrock, K.M. Grayling, S.R. Tracy, R.J. Flavel, I.M Young, et al. 2013. Applications of X-ray computed tomography for examining biophysical interactions and structural development in soil systems: A review. Eur. J. Soil Sci. 64:279-297. doi:10.1111/ejss.12028

Hocking, R.R. 1976. The analysis and selection of variables in linear regression. Biometrics 32:1-49. doi:10.2307/2529336

Horn, R., H. Taubner, M. Wuttke, and T. Baumgartl. 1994. Soil physical properties related to soil structure. Soil Tillage Res. 30:187-216. doi:10.1016/0167-1987(94)90005-1

Hunt, G.R. 1977. Spectral signatures of particulate minerals in the visible and near infrared. Geophysics 42:501-513. doi:10.1190/1.1440721

Islam, K., B. Singh, and A. McBratney. 2003. Simultaneous estimation of several soil properties by ultra-violet, visible, and near-infrared reflectance spectroscopy. Soil Res. 41:1101-1114. doi:10.1071/SR02137

Jarvis, N.J. 2007. A review of non-equilibrium water flow and solute transport in soil macropores: Principles, controlling factors and consequences for water quality. Eur. J. Soil Sci. 58:523-546. doi:10.1111/j.1365-2389.2007.00915.x

Katuwal, S., E. Arthur, M. Tuller, P. Moldrup, and L.W. de Jonge. 2015 a Quantification of soil pore network complexity with X-ray computed tomography and gas transport measurements. Soil Sci. Soc. Am. J. 79:1577-1589. doi:10.2136/sssaj2015.06.0227

Katuwal, S., P. Moldrup, M. Lamande, M. Tuller, and L.W. de Jonge. $2015 \mathrm{~b}$ Effects of CT number derived matrix density on preferential flow and transport in a macroporous agricultural soil. Vadose Zone J. 14(7). doi:10.2136/vzj2015.01.0002

Katuwal, S., T. Norgaard, P. Moldrup, M. Lamandé, D. Wildenschild, and L.W. de Jonge. 2015 c. Linking air and water transport in intact soils to macropore characteristics inferred from X-ray computed tomography. Geoderma 237-238:9-20. doi:10.1016/j.geoderma.2014.08.006

Kennard, R.W., and L.A.Stone. 1969. Computer aided design of experiments. Technometrics 11:137-148. doi:10.1080/00401706.1969.10490666

Knadel, M., F. Masís-Meléndez, L.W. de Jonge, P. Moldrup, E. Arthur, and M.H. Greve. 2016. Assessing soil water repellency of a sandy field with visible near infrared spectroscopy. J. Near Infrared Spectrosc. 24:215224. doi:10.1255/jnirs. 1188

Knadel, M., B. Stenberg, F. Deng, A. Thomsen, and M.H. Greve. 2013a. Comparing predictive abilities of three visible-near infrared spectrophotometers for soil organic carbon and clay determination. J. Near Infrared Spectrosc. 21:67-80. doi:10.1255/jnirs.1035

Knadel, M. R.A. Viscarra Rossel, F. Deng, A. Thomsen, and M.H. Greve. 2013b. Visible-near infrared spectra as a proxy for topsoil texture and glacial boundaries. Soil Sci. Soc. Am. J. 77:568-579. doi:10.2136/sssaj2012.0093

Koestel, J., and M. Larsbo. 2014. Imaging and quantification of preferential solute transport in soil macropores. Water Resour. Res. 50:4357-4378. doi:10.1002/2014WR015351

Köhne, J.M., S. Schlüter, and H.-J. Vogel. 2011 . Predicting solute transport in structured soil using pore network models. Vadose Zone J. 10:1082 1096. doi:10.2136/vzj2010.0158

Kutner, M.H., C.J. Nachtsheim, J. Neter, and W. Li. 2005. Applied linear statistical models. 5th ed. McGraw-Hill, New York.

Lamandé, M., D. Wildenschild, F.E. Berisso, A. Garbout, M. Marsh, P. Moldrup, et al. 2013. X-ray CT and laboratory measurements on glacial till subsoil cores: Assessment of inherent and compactionaffected soil structure characteristics. Soil Sci. 178:359-368. doi:10.1097/SS.0b013e3182a79ela

Larsbo, M., J. Koestel, and N. Jarvis. 2014. Relations between macropore network characteristics and the degree of preferential solute transport. Hydrol. Earth Syst. Sci. 18:5255-5269. doi:10.5194/hess-18-5255-2014

Lindhardt, B., C. Abildtrup, H. Vosgerau, P. Olsen, S. Torp, B.V. Iversen, et al. 2001. The Danish Pesticide Leaching Assessment Programme: Site characterization and monitoring design. Geol. Surv. of Denmark and Greenland, Copenhagen.

Luo, L., H. Lin, and P. Halleck. 2008. Quantifying soil structure and preferential flow in intact soil using X-ray computed tomography. Soil Sci. Soc. Am. J. 72:1058-1069. doi:10.2136/sssaj2007.0179

Luo, L., H. Lin, and S. Li. 2010. Quantification of 3-D soil macropore networks in different soil types and land uses using computed tomography. J. Hydrol. 393:53-64. doi:10.1016/j.jhydrol.2010.03.031

Martens, H., and T. Naes. 1989. Multivariate calibration. John Wiley \& Sons, New York.

Møberg, J.P., L. Petersen, and K. Rasmussen. 1988. Constituents of some widely distributed soils in Denmark. Geoderma 42:295-316. doi:10.1016/0016-7061 (88)90007-9
Mooney, S.J. 2002. Three-dimensional visualization and quantification of soil macroporosity and water flow patterns using computed tomography. Soil Use Manage. 18:142-151. doi:10.1111/j.1475-2743.2002.tb00232.x

Mouazen, A., R. Karoui, J. De Baerdemaeker, and H. Ramon. 2005. Classification of soil texture classes by using soil visual near infrared spectroscopy and factorial discriminant analysis techniques. J. Near Infrared Spectrosc. 13:231-240. doi:10.1255/jnirs.541

Naveed, M., P. Moldrup, M. Schaap, M. Tuller, R. Kulkarni, H.-J. Vögel, and L.W. de Jonge. 2015. Macropore flow at the field scale: Predictive performance of empirical models and X-ray CT analyzed macropore characteristics. Hydrol. Earth Syst. Sci. Discuss. 2015:12089-12120. doi:10.5194/hessd-12-12089-2015

Nawar, S., H. Buddenbaum, J. Hill, J. Kozak, and A.M. Mouazen. 2016. Estimating the soil clay content and organic matter by means of different calibration methods of vis-NIR diffuse reflectance spectroscopy. Soil Tillage Res. 155:510-522. doi:10.1016/j.still.2015.07.021

Nocita, M., A. Stevens, C. Noon, and B. van Wesemael. 2013. Prediction of soil organic carbon for different levels of soil moisture using Vis-NIR spectroscopy. Geoderma 199:37-42. doi:10.1016/j.geoderma.2012.07.020

Nocita, M., A. Stevens, G. Toth, P. Panagos, B. van Wesemael, and L. Montanarella. 2014. Prediction of soil organic carbon content by diffuse reflectance spectroscopy using a local partial least square regression approach. Soil Biol. Biochem. 68:337-347. doi:10.1016/j.soilbio.2013.10.022

Norgaard, T., P. Moldrup, P. Olsen, A.L. Vendelboe, B.V. Iversen, M.H. Greve, et al. 2013. Comparative mapping of soil physical-chemical and structural parameters at field scale to identify zones of enhanced leaching risk. J. Environ. Qual. 42:271-283. doi:10.2134/jeq2012.0105

Norris, K. 2001. Applying Norris derivatives: Understanding and correcting the factors which affect diffuse transmittance spectra. NIR news 12:69.

Paradelo, M., S. Katuwal, P. Moldrup, T. Norgaard, L. Herath, and L.W. de Jonge. 2016. X-ray CT-derived soil characteristics explain varying air, water, and solute transport properties across a loamy field. Vadose Zone J. 15(4). doi:10.2136/vzj2015.07.0104

Peng, Y., M. Knadel, R. Gislum, K. Schelde, A. Thomsen, and M.H. Greve. 2014. Quantification of SOC and clay content using visible nearinfrared reflectance-mid-infrared reflectance spectroscopy with jack-knifing partial least squares regression. Soil Sci. 179:325-332. doi:10.1097/ss.0000000000000074

Rab, M.A., R.E. Haling, S.R. Aarons, M. Hannah, I.M. Young, and D. Gibson. 2014. Evaluation of X-ray computed tomography for quantifying macroporosity of loamy pasture soils. Geoderma 213:460-470. doi:10.1016/j.geoderma.2013.08.037

Rawls, W.J. 1983. Estimating soil bulk density from particle size analysis and organic matter content. Soil Sci. 135:123-125. doi:10.1097/00010694198302000-00007

Rinnan, A.., F. van den Berg, and S.B. Engelsen. 2009. Review of the most common pre-processing techniques for near-infrared spectra. TrAC, Trends Anal. Chem. 28:1201-1222. doi:10.1016/j.trac.2009.07.007

Santra, P., R.N. Sahoo, B.S. Das, R.N. Samal, A.K. Pattanaik, and V.K. Gupta. 2009. Estimation of soil hydraulic properties using proximal spectral reflectance in visible, near-infrared, and shortwave-infrared (VIS-NIR-SWIR) region. Geoderma 152:338-349. doi:10.1016/j.geoderma.2009.07.001

Sarathjith, M.C., B.S. Das, H.B. Vasava, B. Mohanty, A.S. Sahadevan, S.P. Wani, and K.L. Sahrawat. 2014. Diffuse reflectance spectroscopic approach for the characterization of soil aggregate size distribution. Soil Sci. Soc. Am. J. 78:369-376. doi:10.2136/sssaj2013.08.0377

Sauvola, J., and M.Pietikäinen.2000. Adaptive documentimagebinarization. Pattern Recognit. 33:225-236. doi:10.1016/S0031-3203(99)00055-2

Schlüter, S., U. Weller, and H.-J. Vogel. 2011. Soil-structure development including seasonal dynamics in a long-term fertilization experiment. J. Plant Nutr. Soil Sci. 174:395-403. doi:10.1002/jpln.201000103

Shepherd, K.D., and M.G. Walsh. 2002. Development of reflectance spectral libraries for characterization of soil properties. Soil Sci. Soc. Am. J. 66. doi:10.2136/sssaj2002.9880

Soares, A., P. Moldrup, A.L. Vendelboe, S. Katuwal, T. Norgaard, C. Delerve-Matos, et al. 2015. Effects of soil compaction and organic carbon content on preferential flow in loamy field soils. Soil Sci. 180:1020. doi:10.1097/SS.0000000000000105

Sørensen, L.K., and S. Dalsgaard. 2005. Determination of clay and other soil properties by near infrared spectroscopy. Soil Sci. Soc. Am. J. 69. doi:10.2136/sssaj2005.0159 
Stenberg, B., R.A. Viscarra Rossel, A.M. Mouazen, and J. Wetterlind. 2010. Visible and near infrared spectroscopy in soil science. Adv. Agron. 107:163-215. doi:10.1016/S0065-2113(10)07005-7

Tsuchiyama, A., T. Hanamoto, Y. Nakashima, and T. Nakano. 2000 Quantitative evaluation of attenuation contrast of minerals by using a medical X-ray CT scanner. J. Mineral. Petrol. Sci. 95:125-137. doi:10.2465/jmps.95.125

Vanderborght, J., A. Timmerman, and J. Feyen. 2000. Solute transport for steady-state and transient flow in soils with and without macropores. Soil Sci. Soc. Am. J. 64:1305-1317. doi:10.2136/sssaj2000.6441305x

Vaz, C., M. Tuller, P. Lasso, and S. Crestana. 2014. New perspectives for the application of high-resolution benchtop X-ray microCT for quantifying void, solid and liquid phases in soils. In: W.G. Teixeira et al., editors, Application of soil physics in environmental analyses: Measuring, modelling and data integration. Springer, Cham, Switzerland. p. 261281. doi:10.1007/978-3-319-06013-2_12

Viscarra Rossel, R.A., and T. Behrens. 2010. Using data mining to model and interpret soil diffuse reflectance spectra. Geoderma 158:46-54. doi:10.1016/j.geoderma.2009.12.025

Viscarra Rossel, R.A., T. Behrens, E. Ben-Dor, D.J. Brown, J.A.M Demattê, K.D. Shepherd, et al. 2016. A global spectral library to characterize the world's soil. Earth Sci. Rev. 155:198-230. doi:10.1016/j.earscirev.2016.01.012

Viscarra Rossel, R.A., D.J.J. Walvoort, A.B. McBratney, L.J. Janik, and J.O. Skjemstad. 2006. Visible, near infrared, mid infrared or combined diffuse reflectance spectroscopy for simultaneous assessment of various soil properties. Geoderma 131:59-75. doi:10.1016/j.geoderma.2005.03.007

Vogel, H.-J. 2000. A numerical experiment on pore size, pore connectivity water retention, permeability, and solute transport using network models. Eur. J. Soil Sci. 51:99-105. doi:10.1046/j.1365-2389.2000.00275.x
Vogel, H.-J., I. Cousin, O. Ippisch, and P. Bastian. 2006. The dominant role of structure for solute transport in soil: Experimental evidence and modelling of structure and transport in a field experiment. Hydrol. Earth Syst. Sci. 10:495-506. doi:10.5194/hess-10-495-2006

Vogel, H.-J., and K. Roth. 2003. Moving through scales of flow and transport in soil J. Hydrol. 272:95-106. doi:10.1016/S0022-1694(02)00257-3

Vogel, H.-J., U. Weller, and S. Schluter. 2010. Quantification of soil structure based on Minkowski functions. Comput. Geosci. 36:1236-1245. doi:10.1016/j.cageo.2010.03.007

Vohland, M., and C. Emmerling. 201 1. Determination of total soil organic C and hot water-extractable C from VIS-NIR soil reflectance with partial least squares regression and spectral feature selection techniques. Eur. J. Soil Sci. 62:598-606. doi:10.1111/j.1365-2389.2011.01369.x

Waruru, B.K., K.D. Shepherd, G.M. Ndegwa, P.T. Kamoni, and A.M. Sila. 2014. Rapid estimation of soil engineering properties using diffuse reflectance near infrared spectroscopy. Biosyst. Eng. 121:177-185. doi:10.1016/j.biosystemseng.2014.03.003

Wight, J.P., A.J. Ashworth, and F.L. Allen. 2016. Organic substrate, clay type, texture, and water influence on NIR carbon measurements. Geoderma 261:36-43. doi:10.1016/j.geoderma.2015.06.021

Wold, S., M. Sjöström, and L. Eriksson. 2001. PLS-regression: A basic tool of chemometrics. Chemom. Intell. Lab. Syst. 58:109-130. doi:10.1016/S0169-7439(01)00155-1

Yang, H., B. Kuang, and A.M. Mouazen. 2012. Quantitative analysis of soil nitrogen and carbon at a farm scale using visible and near infrared spectroscopy coupled with wavelength reduction. Eur. J. Soil Sci. 63:410-420. doi:10.1111/j.1365-2389.2012.01443.x 